\title{
Contributions of surface and conceptual information to recognition memory
}

\author{
SONYA M. SHEFFERT \\ Central Michigan University, Mt. Pleasant, Michigan
}

\begin{abstract}
The present experiments were designed to determine whether memory for the voice in which a word is spoken is retained in a memory system that is separate from episodic memory or, instead, whether episodic memory represents both word and voice information. These two positions were evaluated by assessing the effects of study-to-test changes in voice on recognition memory after a variety of encoding tasks that varied in processing requirements. In three experiments, the subjects studied a list of words produced by six voices. The voice in which the word was spoken during a subsequent explicit recognition test was either the same as or different from the voice used in the study phase. The results showed that word recognition was affected by changes in voice after each encoding condition and that the magnitude of the voice effect was unaffected by the type of encoding task. The results suggest that spoken words are represented in long-term memory as episodic traces that contain talker-specific perceptual information.
\end{abstract}

Several theories of memory have proposed that the primary determinant of retention of a linguistic event is the degree of semantic encoding the message has received (see, e.g., Anderson \& Bower, 1973; Craik \& Lockhart, 1972). Memory was conceived of as being the end product of several processing stages, beginning with the shallow analysis of surface features of a linguistic event and ending with the deep encoding of semantic information. These theories have assumed that words are stored in memory as abstract types, rather than as specific tokens. For theories of spoken language processing, this would mean that, in order for an acoustic input to be recognized as a particular word, listeners must first convert the signal into a form that can be compared to canonical word representations in lexical memory. Consequently, surface information about the perceptual form of a word, such as voicel information, is presumably discarded during early perceptual processing and is absent from stored word representations (Pisoni, 1996; Studdert-Kennedy, 1974).

The view has been refuted by several studies in which it is demonstrated that variation in the physical realization of a word across the study and test phases of a memory experiment can affect memory retrieval, indicating that a loss of surface information is not a necessary consequence of word recognition and retention (for reviews, see Kolers \& Roediger, 1984; Pisoni, 1993; Richardson-Klavehn \& Bjork, 1988; Roediger \& McDermott, 1993). Conse-

The research presented in this article was supported by NICHD Grant HD-01994 to Haskins Laboratories, NICHD Training Grant DC00012 to Indiana University, and an APA Science Directorate Dissertation Research Award. The author thanks Carol Fowler, Jay Rueckl, David Pisoni, Keith Johnson, and two anonymous reviewers for comments and suggestions. Correspondence should be addressed to S. M. Sheffert, Department of Psychology, Central Michigan University, Mt. Pleasant, MI 48859. quently, exclusively semantic or abstractionist theories of lexical memory are no longer considered tenable. In their place are theories acknowledging that surface information is not lost during early perceptual processing but is stored in long-term memory and can affect word recognition. What is now in question is how surface and conceptual knowledge about a word is represented in memory. The aim of the research to be reported here is to explore in detail the nature of the memory traces that support recognition memory for spoken words. A specific goal is to determine whether memory for the voice in which a word is spoken is retained in a memory system that is separate from the system supporting episodic memory (Schacter \& Church, 1992; Tulving, 1972) or, alternatively, whether a single episodic system represents both voice and word information (Goldinger, 1996; Hintzman, 1986; Roediger, 1990).

At present, there is only a handful of studies that examine the effects of voice change on recognition memory, and the pattern of findings is not consistent. The variable results are important to understand because of their theoretical implications. Some studies report that word recognition effects are independent of the voice in which words were spoken. For example, in an experiment by Jackson and Morton (1984), subjects made animacy judgments to nouns presented in either a male or a female voice. Presenting a word in a voice of the opposite gender from that used at study had no effect on recognition memory. Similarly, Church and Schacter (1994; see also Schacter \& Church, 1992) examined the effects of voice change across study and test on implicit and explicit memory for words. A study phase of their experiment consisted of shallow or deep processing of 24 words spoken in six voices. The voice in which the word was spoken during a subsequent implicit identification test or an explicit recognition test was either the same as or differ- 
ent from the voice used in the study phase. Church and Schacter found that study-to-test changes in voice reduced priming, whereas recognition was indifferent to this manipulation. Conversely, depth of processing affected recognition but not priming.

This double dissociation between variables affecting implicit and explicit memory tasks was interpreted by the authors as evidence that performance on the two tasks is served by distinct memory systems. According to this view, memory is fractionated into several functionally and anatomically distinct systems, each with its own representations and rules of operation (Schacter, 1987; Squire, 1992; Tulving, 1972). Explicit memory task performance is mediated by an explicit (or episodic) memory system, which retains information about the spatial and temporal relations among events, such as when and where a word was encountered. Explicit memory does not represent perceptual word form information and does not contribute to priming on implicit memory tests. In contrast, performance on verbal implicit memory tasks is mediated by a presemantic representational system (PRS; Schacter, 1992; Tulving \& Schacter, 1990) that represents perceptual words forms but not meaning or other associative information.

An important prediction from this view of memory is that sensitivity to changes from study to test in the form of a word should depend on the memory system tapped by a task. If transfer effects are assessed with a recognition test, effects of perceptual form change should not be observed, because recognition is an explicit task performed by a memory system that has no access to the perceptual form of a word. Effects of form change should only be observed on certain implicit tasks that tap the PRS.

An alternative to the memory systems approach proposes that memory tests dissociate because they tap different kinds of cognitive operations or information within a single episodic memory system. According to the transfer appropriate processing view (see, e.g., Jacoby \& Dallas, 1981; Kolers \& Roediger, 1984; Morris, Bransford, \& Franks, 1977; Roediger, 1990) memory transfer is a consequence of the degree to which retrieval conditions reinstate or match the processing operations performed at encoding. Performance on most explicit tests is largely conceptually driven, or determined by the match between conceptual information at study and at test (Roediger, 1990). Transfer is a function of the amount of elaborative encoding at study and tends to be unaffected by changes in the perceptual form of an item. In contrast, performance on most implicit tests is largely data driven, with transfer being determined by the degree to which the sensory form of the test stimuli resembles that of the study stimuli.

The processing approach emphasizes that the contrast between conceptual and perceptual processing is not perfectly parallel with the distinction between explicit and implicit task paradigms (Blaxton, 1989). Accordingly, an explicit task, such as recognition, may involve two processes (Atkinson \& Juola. 1974; Gardiner, 1988; Jacoby \& Dallas, 1981; Mandler, 1980). One process uses concep- tually driven recall-like search procedures to link the test item to a previous episode. A second process uses perceptual or item-specific representations as a basis for responding. When the perceptual match between study and test items is very good, the ease, or fluency, with which the item is processed will increase (Jacoby, 1983). This, in turn, enhances the perceived familiarity of an item and may result in a positive recognition decision in the absence of conscious recollection.

The processing view predicts that study-to-test changes in the perceptual form of a word will affect explicit memory if the task demands favor dependence on perceptual fluency - for example, by minimizing elaborative processing or increasing data-driven processing. Under such conditions, the utility of conceptually based search procedures is reduced, and subjects may rely more on the phenomenal qualities that determine familiarity to make their recognition decisions.

Empirical support for the processing view comes from studies demonstrating that recognition judgments are facilitated when the study and test forms are physically identical. For instance, in an experiment by Goldinger (1996), the subjects identified words at study. After a delay, they received a recognition memory test on the same words; half were repeated in the same voice, half in a different voice. Recognition memory performance was enhanced on same-voice trials over delays between study and test as long as $24 \mathrm{~h}$.

In the recognition experiments mentioned so far, the subjects engaged in a study task, such as identifying or rating the pleasantness of the word and, after a retention interval, performed a recognition memory test. Thus, the processing requirements were considerably different during each encounter with the word. In contrast, the similarity between the first and second presentations of a word is especially high in experiments that use a continuous recognition memory paradigm (Craik \& Kirsner, 1974; Palmeri, Goldinger, \& Pisoni, 1993; Sheffert \& Fowler, 1995), which may explain why voice effects have consistently been found with this procedure. In these studies, words are presented auditorily in a continuous list. Each word is either spoken one time or repeated (in the same voice or in a different voice) after a variable number of intervening items. The subjects are required to decide whether the word just presented is new or old. In each of these experiments, there was a benefit to word recognition on same-voice trials, even when as many as 64 items intervened between occurrences of a word.

As the foregoing review reveals, the presence of voice effects in recognition varies, from strongly present (Craik \& Kirsner, 1974; Goldinger, 1996; Palmeri et al., 1993; Sheffert \& Fowler, 1995) to completely absent (Church \& Schacter, 1994; Schacter \& Church, 1992). The variable outcomes may be partly due to the use of different recognition paradigms (discrete study-test paradigm vs. continuous recognition memory procedure). But even when the latter set of experiments is ignored, a discrepancy in the literature concerning the effects of voice variation on 
recognition memory for spoken words still remains. One potential source of the different outcomes in these remaining experiments is the processing activities evoked by the stimulus materials. In the experiments by Schacter and Church, the subjects heard a relatively small number of low-frequency, concrete words that were usually multisyllabic. Moreover, several items within their list formed paired associates (e.g., lemon and lemonade, shampoo and lather), which may have encouraged organization or interitem elaboration. In contrast, the experiments that found voice effects on recognition memory all used monosyllabic, high-frequency words that could not easily be organized into semantic categories (e.g., shop, case, salt, group, told). From a processing perspective, the voice that produced a word may affect recognition memory if task demands favor dependence on familiarity - for example, by decreasing elaborative rehearsal (Mandler, 1980). Under these conditions, contextual information is weak, and intentional retrieval processes are less reliable; thus, subjects' old/new judgments are likely to be based on familiarity. In contrast, the contribution of perceptual information to recognition memory has been found to diminish as elaborative processing increases (Gardiner, Gawlik, \& Richardson-Klavehn, 1994; Jacoby \& Witherspoon, 1982; Johnston, Hawley, \& Elliot, 1991).

If the explicit conditions that result in null sensitivity to voice information are restricted only to the most conceptually driven settings, the claim that voice information is retained in a memory system that is separate from the system supporting episodic memory (see Schacter \& Church, 1992) is weakened. A stronger test of the systems and process views can be accomplished by adopting aspects of the experimental design and tasks of Schacter and Church, such as their study-test paradigm and levels-ofprocessing encoding tasks, but using a less distinctive set of words and a more conservative voice manipulation and varying the processing demands at study over a wider range. This report provides that test.

To accomplish this, several different study conditions were manipulated in an effort to determine the specific encoding circumstances that promote voice-specificity effects. In Experiment 1, the contribution of a physical match between the study and the test list was evaluated by presenting study words either in the clear or degraded by the masking effects of noise. In Experiment 2, the importance of a conceptual processing match was assessed by requiring the subjects to complete either a nonsemantic or a semantic processing task at study. In Experiment 3, the extent to which spoken word intelligibility affects the assessment of a voice effect was evaluated by requiring listeners to identify study and test words and then conditionalizing performance on correct word identification. In all three experiments, the subjects studied a list of 120 monosyllabic words that were not obviously distinctive and did not lend themselves to interitem organization (see the Appendix). The study phase was followed by a surprise recognition memory test in which old words were repeated in a voice that was the same as or different from that in the study phase. When a voice change occurred across study and test, it was always within the same gender. This voice manipulation is more subtle and conservative than the voice manipulation used by Schacter and Church (1992) and ensures that the effects of voice change were not confounded with the effects of gender change.

These experiments also sought to determine whether different encoding tasks affect the voluntary and involuntary retrieval of voice information. This question was addressed by using a variation of the conventional new-old recognition test. The recognition task used in Experiments 1 and 2 required listeners to make explicit speaker judgments on old trials. That is, if a subject recognized a word as a repetition from the study phase, he or she also had to decide whether it was repeated in the same voice or in a different voice. Previous research comparing this task with the conventional new-old recognition paradigm has demonstrated that the additional explicit speaker judgment does not produce differences in the overall accuracy of word recognition or in the size of the voice effect (Palmeri et al., 1993; Sheffert \& Fowler, 1995). The advantage of this particular recognition paradigm is that one can explore word and voice recognition and the relation between the voice-specificity effects and the accuracy of explicit voice judgments. For example, given that explicit memory improves as the level of processing becomes deeper, explicit memory for the voice that produced a word may also benefit from elaboration at study. Compatibly, it is possible that there may be a tradeoff in the size of the implicit voice effect and the accuracy of explicit voice judgments.

\section{EXPERIMENT 1}

In Experiment 1, the acoustic form of the study list was varied in order to determine whether the physical similarity of the study and test lists affects the retrieval of voice information. At study, the subjects were presented with a list of words produced by six talkers. One group of subjects identified words spoken in the clear, and a second group identified words embedded in white noise. After a brief delay, a recognition memory test was administered in which an equal number of studied and unstudied items was presented, with an equal number of studied words repeated in a voice that was the same as or different from that in the study phase. ${ }^{2}$ The recognition test required listeners to make judgments about voice-word pairings on old trials. That is, when a subject judged a word to be old, he or she made a second judgment as to whether the talker saying the word on the second occurrence was the same as or different from the talker saying the word on its first occurrence. The dependent measure was accuracy.

The multiple memory systems view predicts that recognition should be unaffected by voice mismatches because it involves an explicit task performed using episodic memory, which has no access to perceptual word form information in the PRS. With regard to clear identification and noise identification study tasks, the direction of the effect of this manipulation remains unspecified. 


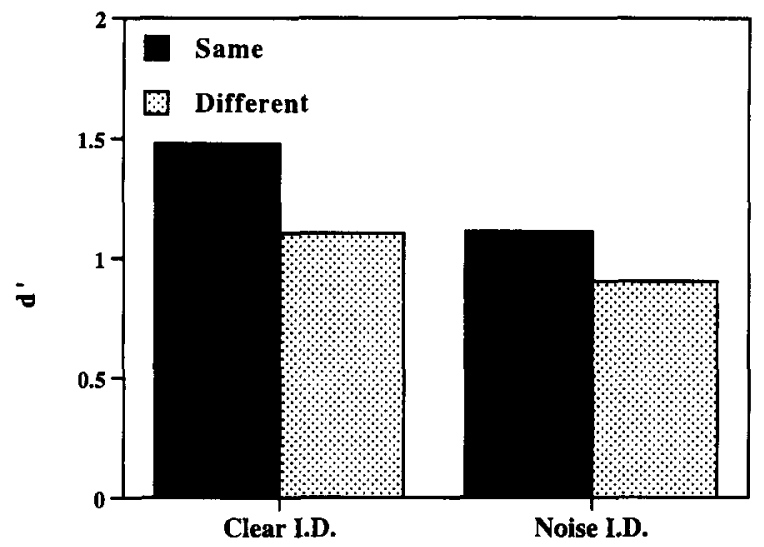

Study

Figure 1. Mean $d^{\prime}$ values reported in Experiment 1. The data are presented as a function of study condition and speaker's voice.

The transfer-appropriate processing view predicts that voice effects will be present in explicit memory when conditions encourage dependence on familiarity. Moreover, if the traces that support word recognition include information about the processing operations required to encode the stimulus, as this view supposes, the different encoding tasks may produce differences in the magnitude of voice-specific retrieval. Specifically, the processing view predicts that voice-specific transfer will be enhanced when both the encoding and the test lists are in the same physical form (i.e., words presented in the clear at study and at test).

\section{Method}

Subjects. Thirty University of Connecticut undergraduate students volunteered for this experiment in exchange for partial course credit or payment. All the subjects were native speakers of English, with normal hearing and normal or corrected vision at the time of testing.

A $2 \times 2$ mixed factorial design was used. The between-subjects variable was study condition (identification of words in the clear or in noise). The within-subjects variable was voice (same or different). Fifteen subjects were randomly assigned to each of the study conditions.

Materials. The stimuli were 250 monosyllabic words selected from the Kučera and Francis ( 1967 ) frequency norms and the Modified Rhyme Test (House, Williams, Hecker, \& Kryter, 1965). Audio recordings were obtained by asking six different speakers (three males and three females) to read each item in citation form (talkers carefully pronounced each word and maintained a flat intonation). The words were recorded in a sound-proof booth and then digitized at a $10.4-\mathrm{kHz}$ sampling rate and equated for peak amplitude. Each word was recorded by every speaker, and, from these items, 20 experimental tokens ( 10 designated as same-voice repetitions, and 10 as different-voice repetitions) and 20 control fillers produced by each speaker were randomly selected for use in the final stimulus tape. An additional 10 tokens were randomly selected as primacy and recency buffers for the study list.

A total of 130 words ( 120 target words. five primacy, and five recency buffer items) were presented at study. One study tape presented words in the clear, and a second presented words in white noise (signal-to-noise ratio of $-5 \mathrm{~dB}$ ). The onset and offset of the noise coincided exactly with the onset and offset of the word. The test tape presented 240 clearly spoken words in a random order. One hundred twenty words were from the study phase and 120 words were new fillers. Of the 120 studied words, 60 were repeated in the same voice and were the same tokens used as study items, and 60 were repeated in a different voice of the same gender. In both the study and test tapes, a new word was spoken every $5 \mathrm{sec}$.

A pretest was conducted to assess the intelligibility of the stimulus materials. Two separate groups of 15 listeners identified each of the words in the study lists (words in the clear and words in noise). A third group of 15 different listeners identified the words in the test list. The intelligibility of the words (i.e., percent correct identification of each word by the listeners) was $88 \%$ for the clear study list, $55 \%$ for the noise study list, and $87 \%$ for the test list. These values are well within the normal range of intelligibility for monosyllabic words (Miller, Heise, \& Lichten, 1951). Moreover, there was no difference in the intelligibility of same-voice and different-voice study items and, for the test list, no difference in the intelligibility of the same-voice, different-voice, and filler items.

Procedure. The subjects were tested in groups of 4 or fewer in a quiet room. The study and test stimuli were presented over headphones, and the subjects recorded their responses on answer sheets. Prior to study, the subjects were told that they were providing normative data for a different experiment and were not informed that their memory would be tested later. During the study phase, the subjects heard 130 words spoken by six speakers. The first 5 and last 5 words served as primacy and recency buffers and were not included in the data analysis. In the identification tasks, the subjects listened to each word and wrote its spelling on their answer sheet, guessing if necessary. After the study phase, the subjects engaged in a filler task, for 4.5-5 min, in which they completed a series of mathematical problems.

After the filler test, the subjects received a surprise recognition test in which they heard 240 words, half of which were studied words, with an equal number of words repeated in a voice that was the same as or different from that in the study phase. When a voice change occurred across study and test, it was always within gender. The recognition test required the subjects to make two forcedchoice judgments under an explicit retrieval orientation: a word recognition memory judgment and an explicit voice recognition memory judgment. Specifically, the subjects responded new if the word was not present during the study phase. If they judged a word to be old, they were also required to decide whether the word was repeated in the same or a different voice. They were instructed to indicate their response by circling new, old-same, or old-different on their answer sheet. The experimental session lasted less than $45 \mathrm{~min}$, after which subjects were debriefed.

\section{Results}

Word recognition. To analyze word recognition performance, explicit voice judgments (old-same and olddifferent responses) were pooled to create a single old category. Word recognition performance was conditionalized on correct word identification at study. ${ }^{3}$ The recognition scores (proportion of hits - false alarms) were .46 for same-voice trials and .34 for different-voice trials after clear identification, and .29 for same-voice trials and .23 for different-voice trials after noise identification. Figure 1 displays the $d^{\prime}$ values as a function of voice and study condition. The figure shows that, across both study conditions, word recognition was more accurate when the voice was the same across study and test than when a different voice produced the word at study.

In this experiment and all others reported here, a statistical analysis was performed on both the recognition scores and the $d^{\prime}$ scores. Both analyses consistently led to 


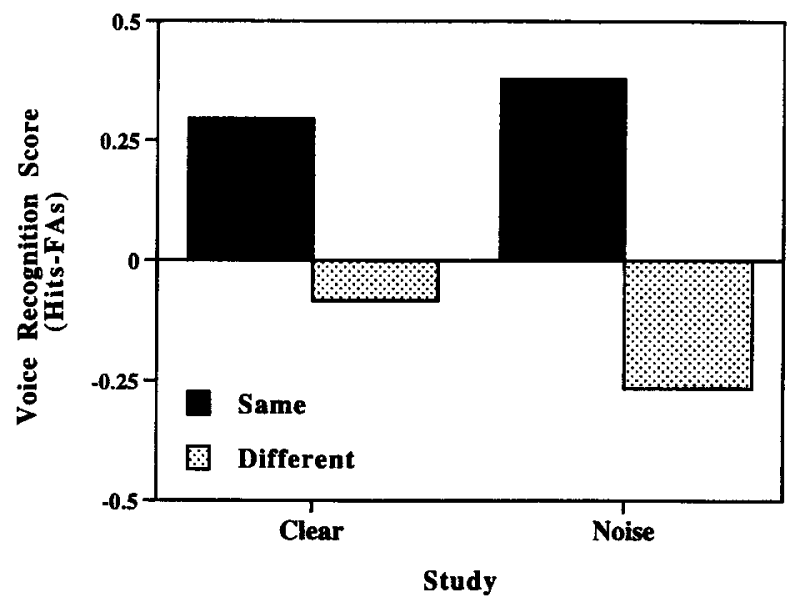

Figure 2. Mean explicit voice recognition scores (hits - false alarms) reported in Experiment 1. The data are presented as a function of study condition and speaker's voice.

the same conclusions. Consequently, only the statistical analysis based on $d^{\prime}$ scores is presented. For the present experiment, the analysis included the within-subjects factor of voice (same voice or different voice) and the between-subjects factor of study task (clear or noise identification). A .05 level of significance was used to interpret all statistical comparisons. A highly significant main effect of voice $\left[F(1,28)=16.55, M S_{\mathrm{e}}=0.11\right]$ on recognition memory was found. The subjects were reliably more accurate on same-voice trials, as compared with different-voice trials. Planned $t$ tests comparing sameand different-voice trials for each study condition indicated that same-voice repetitions were better recognized than different-voice repetitions trials after clear identification $\left[t(14)=3.92, R M S_{\mathrm{e}}=0.095\right]$ and noise identification $\left[t(14)=2.31, R M S_{\mathrm{e}}=0.089\right]$. Not surprisingly, word recognition was significantly higher for subjects who identified words in the clear at study, as compared with subjects who identified words in noise at study $[F(1,28)=$ 4.334, $M S_{\mathrm{e}}=0.29$ ]. Although there tended to be larger voice effects after the clear study condition ( $12 \%$ difference in recognition scores; .39 difference in $d^{\prime}$ scores), as compared with the noise encoding condition ( $6 \%$ difference in hit rates; .21 difference in $d^{\prime}$ scores), the interaction between voice and study group was not significant, indicating that the magnitude of the voice effect was not reliably different across the two study conditions.

These results show that recognition memory performance was affected by study-to-test changes in voice in both identification encoding conditions and that word recognition was reduced when subjects identified perceptually degraded words at study. Moreover, the type of identification task had no significant effect on the size of the voice effect.

Voice judgments. To assess the subjects' ability to retain information about the voice and word pairings, their performance on the old-same and old-different explicit voice judgments were analyzed. Voice recognition scores (proportion of hits minus proportion of false alarms) were calculated separately for old-same and old-different trials. These data are displayed in Figure 2.

The statistical analysis assessed whether the recognition score (hits - false alarms) differed reliably from zero (or chance recognition). Given that an item was judged old, overall performance in identifying the voice as the same or different across word repetitions exceeded zero $[F(1,28)=$ $\left.20.293, M S_{\mathrm{e}}=0.010\right]$. Planned $t$ tests comparing voice recognition on same- and different-voice trials for each study condition indicated that overall voice recognition performance was significantly different from chance after clear study $\left[t(14)=5.71, R M S_{\mathrm{e}}=0.005\right]$ but was not significantly different from zero after noise study.

There was also a significant interaction between the voice condition (same vs. different) and voice recognition performance (observed vs. chance) $[F(1,28)=50.99$, $\left.M S_{\mathrm{e}}=0.134\right]$. This interaction confirms the patterning seen in Figure 2, in which performance exceeds zero on same-voice trials but not on different-voice trials. This patterning of above-chance performance on same-voice repetitions and below-chance performance on differentvoice repetitions indicates that subjects tended to respond same voice when they detected an old item but were uncertain which talker originally produced it. An explanation for this effect is provided in the discussion. There were no other significant effects.

\section{Discussion}

The objective of this experiment was to determine whether study-to-test changes in voice affect recognition memory for spoken words and to determine the extent to which a voice effect depends on the physical similarity of the study and test list. The most important result from Experiment 1 was the finding that, across both encoding conditions, the subjects were more accurate at recognizing old words as such when the same voice, rather than a different voice, produced the word on the first and second occasions. This sensitivity to the voice match between study and test phases occurred despite the fact that the subjects were not instructed to intentionally encode voice information at study.

This finding is consistent with data from Goldinger (1996), who used a study-test recognition design similar to that in Experiment 1. The results are also in agreement with data from Craik and Kirsner (1974), Palmeri et al. (1993), and Sheffert and Fowler (1995), all of whom reported a recognition advantage for same-voice word repetitions, using a continuous recognition memory paradigm. The results from Experiment 1 run counter to the claim that access to voice information on recognition tests is limited to conditions that require listeners to link voice information to semantic speaker information, such as gender (see, e.g., Geiselman \& Bellezza, 1977) or that the effects are only observed when a continuous recognition task is used and when the delay between first and second presentations is very brief (see, e.g., Craik \& Kirsner, 1974; cf. Schacter \& Church, 1992). More generally, the finding of voice effects on word recognition reinforces 
the proposal that spoken words are represented in longterm memory as episodic traces that contain detailed perceptual information and are recognized by direct similarity to prior episodes stored in memory (Jacoby, 1983).

This finding disagrees with data from Church and Schacter (1994) and Schacter and Church (1992). They found that study-to-test changes in voice reduced repetition priming but not recognition. A difference between the present experiment and theirs is that, in the study phase of the present experiment, the subjects identified words, whereas in the study phase of Church and Schacter's experiments, the subjects made nonsemantic or semantic judgments. It is possible that the discrepant outcomes are the result of the different encoding tasks. This issue is directly addressed in Experiment 2.

The data from Experiment 1 also show that the physical similarity of the study and test lists affects the retrieval of words. That is, overall word recognition was more accurate when the subjects studied words that were not embedded in noise. In addition, voice effects were numerically largest after the clear study condition, which suggests a tendency for greater transfer of voice information when the acoustic forms of the study and test lists match.

In addition to assessing the extent to which a voice match facilitates word recognition, Experiment 1 also tested whether information about the voice that produced a word was available for explicit retrieval. The findings show that explicit memory for the voice with which a word is spoken is retrieved with an accuracy better than chance after clear study, but not after noise study. However, closer inspection of the data shows that explicit voice recognition was only above chance on same-voice repetitions. Explicit voice recognition was below chance when the voice that produced the repetition was different. That is, if the subjects were unable to recollect who produced the word at study, they tended to respond same voice more often than different voice. The consequence of this response strategy was to inflate accuracy on samevoice repetitions and to inflate the error rate on differentvoice repetitions.

A similar pattern of above chance explicit memory for the physical form of a word, coupled with a tendency to respond same (Craik \& Kirsner, 1974; Hintzman, Block, \& Inskeep, 1972) has been found by other researchers. Findings from a more recent study by Palmeri et al. (1993) clarified matters by demonstrating that the ability to make accurate judgments about a word-voice pairing varies as a function of the discriminability of the voices. In their design, when a word was repeated in a different voice, the voice was either of the same gender or of a different gender. That is, there were different-voice-samegender repetitions and different-voice-different-gender repetitions. Palmeri et al. found that explicit voice recognition was more accurate for same-voice repetitions than for different-voice repetitions and that performance on different-voice-different-gender repetitions was as accurate as on same-voice repetitions. However, subjects were at chance on different-voice-same-gender repetitions. In the present report, all voice changes were within the same gender. The fact that the discriminability among sameand different-voice tokens was probably not very high would account for the below-chance performance on different-voice trials.

Listeners' ability to recognize or discriminate voices within a response set depends not only on the relative similarity of the voices, but also on the familiarity of the voices. In this experiment, the subjects were not familiar with the talkers, and this may have affected their ability to recollect the voice that produced a particular word during the study phase. Other researchers have shown that listeners are quite accurate at recognizing and identifying familiar or famous voices, even when the test utterances are rate-altered (Van Lancker, Kreiman, \& Wickens, 1985), reversed (Van Lancker, Kreiman, \& Emmorey, 1985), or sinewave analogs of naturally produced utterances (Remez, Fellowes, \& Rubin, 1997). Further research is needed to determine the role that speaker familiarity plays on the involuntary retrieval of voice information during word recognition and on judgments of word-voice pairings.

In summary, in Experiment 1, voice information influenced the accuracy of word recognition, despite the fact that explicit memory for the voices was overall quite weak. This finding is consistent with the idea that voice effects arise from the unintentional or involuntary retrieval of voice information during word identification and not from the explicit recollection of voice information during word identification.

\section{EXPERIMENT 2}

The aim of Experiment 2 was to evaluate the importance of study-to-test changes in voice and depth of study processing on word and voice recognition. The study tasks required subjects to rate the clarity of enunciation of a word or to provide the number of meanings for each word. The recognition test presented half the target words in the same voice as that used during study and half in a different voice. Experiment 2 also tested whether voice information was available for explicit retrieval, by requiring listeners to make judgments about voice-word pairings on old trials. Given that explicit memory for words is strongly affected by depth of study processing, it is possible that explicit memory for word-voice pairings may also be affected by the semantic versus nonsemantic encoding manipulation.

\section{Method}

Materials. The stimulus materials were identical to those used in Experiment 1, except that the subjects only studied items that were presented in the clear.

Subjects and Design. The subjects were 30 undergraduate students at the University of Connecticut. Subjects either volunteered in exchange for partial course credit or were paid \$6. All the subjects were native speakers of English, with normal hearing and normal or corrected vision.

A $2 \times 2$ mixed factorial design was used. The between-subjects variable was study condition (clarity or meaning judgments). Fifteen subjects were randomly assigned to each of the study conditions. The within-subjects variable was voice (same or different). 


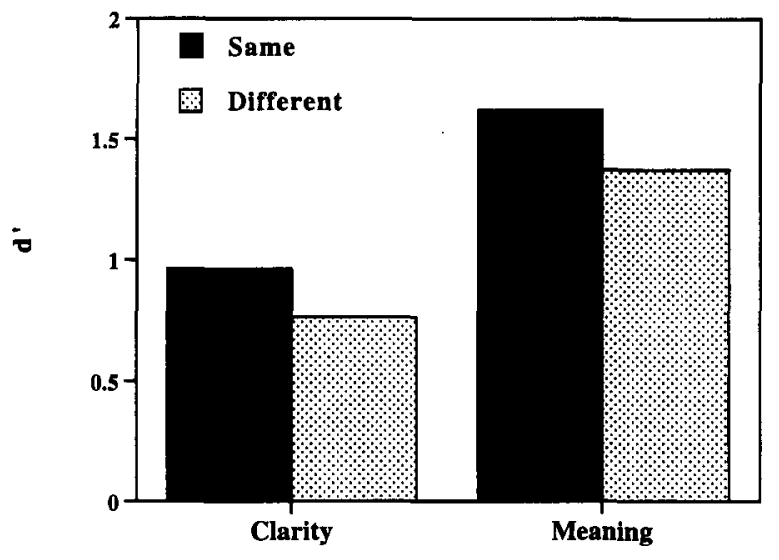

Study

Figure 3. Mean $d^{\prime}$ values reported in Experiment 2. The data are presented as a function of study condition and speaker's voice.

Procedure. The procedures used in Experiment 2 were identical to those in Experiment 1, except that the subjects made nonsemantic or semantic judgments about each word, rather than identifying each word. The subjects making clarity judgments were instructed to rate how clearly a given word was enunciated, whereas the subjects making meaning judgments rated the number of meanings a word had. Both groups used a 4-point scale. After the study phase, the subjects completed the filler task used in Experiment 1 . During the test phase, the subjects heard 240 words, half of which were studied words, with an equal number of same-voice and different-voice repetitions. As in the previous experiment, the subjects were instructed to decide whether a word was new or old, and, if they judged it to be old, they were also required to decide whether the word was repeated in the same or a different voice. The experimental session lasted less than $45 \mathrm{~min}$, after which the subjects were debriefed.

\section{Results}

Word recognition. To assess word recognition, explicit voice judgments ( old-same and old-different) were combined to create a single old category. The recognition scores (hits - false alarms) were .33 for same-voice trials and .27 for different-voice trials after clarity judgments, and .54 for same-voice trials and .48 for differentvoice trials after meaning judgments. The corresponding $d$ 'values are displayed as a function of voice and study condition in Figure 3.

An analysis of variance (ANOVA) was conducted on the $d^{\prime}$ scores, with the within-subjects factor of voice (same voice or different voice) and the between-subjects factor of study task (enunciation or meaning). The analysis revealed a highly significant effect of voice on word recognition accuracy $\left[F(1,28)=21.59, M S_{\mathrm{e}}=0.01\right]$, indicating that recognition memory for spoken words was better when the same voice produced a given word at both study and test. Within each study condition, same-voice repetitions were better recognized than different-voice repetitions after nonsemantic processing $[t(14)=2.69$, $\left.R M S_{\mathrm{e}}=0.073\right]$ and semantic processing $[t(14)=4.02$, $\left.R M S_{\mathrm{e}}=0.062\right]$. A main effect of study task $[F(1,28)=$ $\left.13.75, M S_{\mathrm{e}}=0.44\right]$ on recognition memory was also found, reflecting the fact that the subjects were signifi- cantly more accurate at deciding whether a word was new or old if they had encoded the word deeply. Finally, the interaction between study condition and voice was not significant. This indicates that the size of the implicit voice effect on word recognition did not vary as a function of depth of processing at study.

Voice judgments. The subjects' ability to encode and retain information about the voice and word pairings was assessed by analyzing their performance on the old-same and old-different explicit voice judgments. As in Experiment 1 , voice recognition scores (hits - false alarms) were calculated separately for old-same and old-different trials, and the analysis assessed whether the recognition score (hits - false alarms) differed reliably from zero (or chance recognition). These data are displayed in Figure 4.

Given that an item was judged old, overall performance in identifying the voice as the same or different across word repetitions exceeded zero $\left[F(1,28)=21.03, M S_{\mathrm{e}}=\right.$ $0.006]$. Planned $t$ tests comparing voice recognition on same- and different-voice trials for each encoding condition showed that voice recognition exceeded zero after clarity judgments $\left[t(14)=4.41, R M S_{\mathrm{e}}=0.003\right]$ and was marginally different from zero after meaning judgments at study $\left[t(14)=2.08, R M S_{\mathrm{e}}=0.003, p=.06\right]$.

The interaction between the voice condition (same vs. different) and chance performance (zero) was also significant $\left[F(1,28)=88.53, M S_{\mathrm{e}}=0.027\right]$. As in Experiment 1 , performance on same-voice trials exceeded zero, whereas performance on different-voice trials was consistently below zero. Finally, the lack of an interaction between study condition and voice recognition performance indicates that the ability of the subjects to make recognition decisions about the voice that produced a word was not influenced by depth of processing at study.

\section{Discussion}

Experiment 2 assessed the effects of a voice match on word and voice recognition after one of two study tasks

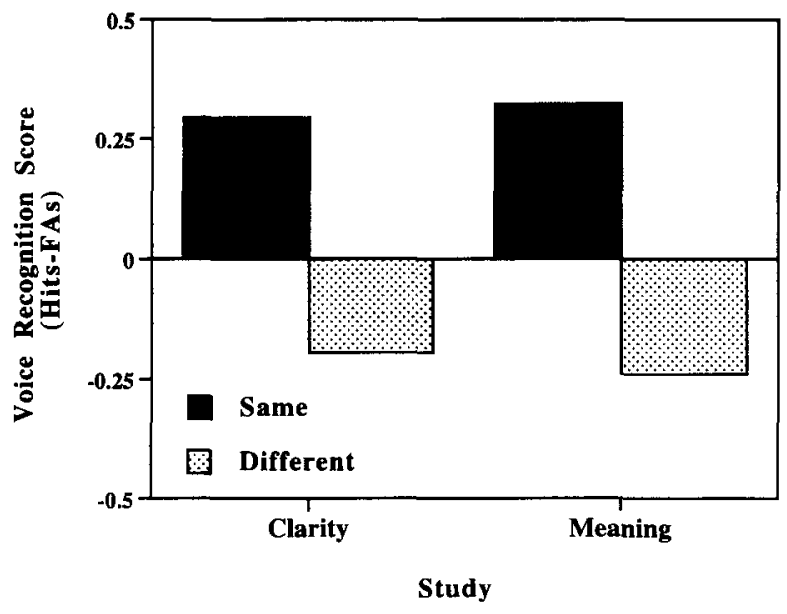

Figure 4. Mean explicit voice recognition scores (hits - false alarms) reported in Experiment 2. The data are presented as a function of study condition and speaker's voice. 
that varied depth of processing. The critical finding was that same-voice repetitions were recognized more accurately than different-voice repetitions, a finding that is consistent with the data from Experiment 1 . The fact that Experiment 2 used the same study-test design and encoding tasks as the experiments reported by Schacter and Church (1992) and Church and Schacter (1994) but a different set of words indicates that the nature of the stimulus materials may be an important determinant of voicespecificity effects in explicit memory. This discrepancy may mean that it is less likely that voice information will be used as a basis for word recognition judgments when other types of organization are present or when the materials are especially distinctive. Alternatively, the presence or absence of voice effects may be related to another aspect that differs across the stimulus materialsword intelligibility. This latter possibility is described and evaluated in Experiment 3.

Experiment 2 also produced the standard levels-ofprocessing effect and further showed that the benefit accruing to same-voice trials was consistent in magnitude across both shallow and deep levels of processing. In fact, the difference between same- and different-voice trials was nearly identical after enunciation judgments and meaning judgments. This shows that voice-specificity effects do not require an orienting task that directs subjects' attention to perceptual aspects of the word.

This particular finding differs from the results reported by Goldinger (1996; see also Geiselman \& Bjork, 1980). In his study, word recognition performance was most susceptible to the effects of a voice mismatch after shallow encoding. However, his levels-of-processing manipulation was very different from the tasks used in this report, making it difficult to compare. If there is a tendency for voice specificity effects to be exaggerated on explicit tasks after nonsemantic encoding, there was no evidence of it in this experiment.

Although the finding of voice effects on the recognition of spoken words can be easily accounted for by a processing framework (Mandler, 1980; Roediger, 1990), the additional finding of equal voice effects across shallow and deep processing conditions is inconsistent. But this finding agrees with other experiments that report that the size of the voice effect is largely unaffected by secondary tasks that focus attention on different aspects of the word event. For example, in a continuous word recognition task that presented both voice and visible speaker information, making perceptual or semantic secondary judgments about the words (Sheffert, Fowler, Steinnagel, \& Behnken, 1995) or about the talkers who produced the words (Sheffert \& Fowler, 1995; see also Palmeri et al., 1993) did not change the size of the voice effect, relative to a condition that required no processing over and above the new-old recognition decision. Similar effects have been found, using a discrete study-test recognition memory paradigm (Goldinger, 1992). Thus, it appears that depth of processing has a large effect on the retrieval of word information but a small effect on the retrieval of perceptual information, even in the context of an explicit memory task. Perhaps levels-of-processing manipulations have little influence on the magnitude of voice effects simply because recognition decisions are based predominately on conceptual information, with perceptual information typically making only a small contribution. Consequently, the range within which perceptual speaker information can influence word recognition may be too narrow to consistently reveal such effects.

Finally, in Experiment 2, there was no evidence of a tradeoff between the size of the voice effect and the overall accuracy in recognizing voices explicitly (see Kirsner, 1973). This failed to occur because the size of the voice effect did not vary as a function of depth of processing (hence, there was nothing to trade off to) and because the levels-of-processing manipulation had no effect on the accuracy of explicit voice recognition. In both cases, speaker recognition was weak. Examination of the differences between observed and chance performance did not reveal any systematic relationship between the type of encoding and accuracy in voice recognition. In particular, explicit memory for the voice that produced a word did not improve after semantic encoding, nor did it vary when the subjects focused their attention on surface features of the word-voice pairings at study, as they did when making enunciation judgments. The fact that the levels-of-processing manipulation had no effect on the involuntary retrieval of voice information during word recognition or on the explicit retrieval of speaker judgments may mean that the same perceptual trace underlies voice-specific retrieval across both the tasks.

\section{EXPERIMENT 3}

In Experiments 1 and 2, voice effects were observed after a range of encoding tasks. However, before concluding that voice effects can be reliably found in recognition memory, one must be sure that the effects are indeed the result of a voice change and not a consequence of word intelligibility. ${ }^{4}$ Recognition memory experiments typically assume that item identification is perfect and assess only the oldness or newness of the stimulus at test. However, it is difficult to ensure that all spoken items are perfectly intelligible to all listeners. A major factor affecting word intelligibility is the confusability of the particular consonants and vowels that compose the item (see Miller \& Nicely, 1955). The intelligibility of a word token also varies both across and within talkers because of differences in glottal characteristics, vocal tract configuration, and speaking style. Finally, intelligibility is affected by the perceptual space of the listener. For example, the words pen and pin may be perceived as the same word by one listener or as two distinct words by another listener. Thus, even perfectly intelligible items may nevertheless by perceived as different words by different listeners (Hood \& Poole, 1980).

Because word intelligibility interacts with talker and listener characteristics, it is possible that the findings 
from Experiments 1 and 2 are not informing us about what happens when a subject perceives a different voice producing a studied word but, instead, are only informing us about what happens when a subject perceives a different word.

Experiment 3 was designed to separate the effects of intelligibility from the assessment of a voice effect, by requiring the subjects to identify words at both study and test and then excluding misheard study and test items from the recognition analysis. For each trial of the study phase, the subjects judged the clarity of the word (as in Experiment 2) and then identified the word by writing its spelling. Similarly, the test phase asked the subjects to decide whether a word was new or old and then to identify the item. Half the target words were same-voice repetitions, and half were different-voice repetitions. If voice effects are observed under these conditions, we will know that it is a change in the voice, rather than a change in the perceived word, that is responsible. If, instead, voice effects are absent in this condition, we will have evidence that the presence or absence of a voice effect in recognition memory is, in part, a function of stimulus ambiguity.

\section{Method}

Materials. The stimulus materials were identical to those used in the previous experiment.

Subjects and Design. The subjects were 15 undergraduate students at Indiana University. The subjects volunteered in exchange for partial course credit. All the subjects were native speakers of English, with normal hearing and normal or corrected vision.

Procedure. During the study phase of this experiment, the subjects carried out two tasks on each trial. First, they rated how clearly a given word was enunciated on a 4-point scale. After making this judgment, they identified the word by writing its spelling on an answer sheet. After the study phase, the subjects completed the same filler task used in the previous experiments. At test, the subjects were instructed to indicate whether the word had occurred in the study phase by circling new or old on their answer sheets. After making this decision, they were then required to write down the word they heard in a space next to the circled response.

\section{Results and Discussion}

In this experiment, correctly identified test items were analyzed only if corresponding study items were also correctly identified. As in the previous experiments, the subjects were better able to recognize old words as such when they were repeated in the same voice rather than in a different voice at test. The recognition scores (proportion of hits - false alarms) were .50 for same-voice trials and .46 for different-voice trials. A $t$ test on the corresponding $d^{\prime}$ scores confirmed that same-voice repetitions $\left(d^{\prime}=\right.$ 1.53) were better recognized than different-voice repetitions $\left[d^{\prime}=1.33 ; t(14)=2.22, R M S_{\mathrm{e}}=0.021\right]$. This result shows that controlling for stimulus ambiguity did not eliminate the influence of voice information on word recognition and demonstrates that voice effects arise from a voice change per se.

A second analysis was conducted to determine whether removal of misheard items at both study and test resulted in a significant reduction in the size of the voice effect. The analysis compared the data from the present exper- iment with the data from the nonsemantic study condition in Experiment 2, in which all the test items contributed to the recognition analysis, despite the fact that some study and test words were misheard. An ANOVA was performed on the $d^{\prime}$ scores from both experiments and included the within-subjects factor of voice (same voice or different voice) and the between-subjects factor of study task (clarity judgments alone or clarity judgments with word identification). There was a main effect of voice $\left[F(1,28)=11.48, M S_{\mathrm{e}}=0.051\right]$. There was also an effect of study task $\left[F(1,28)=12.13, M S_{\mathrm{e}}=0.40\right]$, reflecting the fact that overall word recognition performance was higher for subjects who both rated the clarity with which a word was enunciated and identified the word. More importantly, however, there was no interaction between voice and study group, indicating that the magnitude of the voice effect was not reliably different across the two study conditions (same-voice - different-voice $d^{\prime}$ scores were .20 for each condition). This finding shows that the voice effects in the previous experiments were not a consequence of stimulus ambiguity due to differences in intelligibility.

\section{GENERAL DISCUSSION}

The present experiments were designed to determine whether memory for the voice in which a word is spoken is retained in a memory system that is separate from episodic memory or, instead, whether episodic memory represents both word and voice information. These two views were evaluated by assessing the effects of study-to-test changes in voice on recognition memory after a range of encoding tasks.

The major findings were the following. First, reliable voice effects were found on recognition of spoken words after five different encoding conditions. Second, the physical form and the depth of processing at study affected the overall accuracy of recognition memory but had no effect on the retrieval of voice information. Third, controlling for stimulus ambiguity did not eliminate the influence of voice information on word recognition. Fourth, explicit memory for voices was above chance and did not vary as a function of depth of study processing.

Comparisons across the study conditions revealed that explicit word recognition was superior for semantically encoded items. Counting the number of meanings for each word presumably required more conceptual processing than did rating the clarity of its enunciation or writing its spelling. Accordingly, this finding reflects the expected effect of depth of processing on explicit memory performance. Recognition was poorest for words studied in noise.

Explicit memory for the voice that produced a given word was, overall, above chance, although the subjects were inclined to judge that the voice was the same between new and old presentations of a word, perhaps because different-voice trials were always of the same gender. Moreover, explicit memory for voice was unaffected by the amount of conceptual processing at study, and there 
was no evidence that the size of the voice effect varied as a function of the accuracy of explicit voice or word recognition. In addition, the fact that explicit memory for voice information was weak indicates that voice effects are not due to explicit recollection but instead reflect involuntary retrieval of perceptual information.

Of greater interest is the role of voice information in explicit memory for spoken words. Experiment 1 showed that the subjects were more accurate at recognizing old words as such when the same voice, rather than a different voice, produced the word on the first and second occasions. Moreover, the magnitude of the voice effect on recognition performance did not vary across the five encoding conditions, nor did it correlate with overall recognition accuracy levels. A similar pattern has been observed in parallel tests of implicit memory (Sheffert, 1998).

The fact that voice affected recognition memory is consistent with the proposal that recognition judgments are based on two processes - one conceptual and one perceptual (Atkinson \& Juola, 1974; Jacoby \& Dallas, 1981; Mandler, 1980). On the one hand, word recognition can be accomplished by recalling the original episode, a process that will be easier if one has associated a study item with other items within a list or with knowledge in longterm memory. On the other hand, recognition can also be accomplished by judging perceptual fluency, which imparts a subjective sense of having recently encountered a particular item and can produce a positive recognition decision, even in the absence of conscious recollection of the study event. In this view, the small recognition advantage because of voice consistency may be due to perceptual fluency. Perhaps this may also account for the same bias found in explicit memory for voice-word pairings: The subjects may have misattributed the fluent processing of a repeated word in a different voice as evidence that the voice was originally paired with the word and thus may have been inclined to respond same to a different-voice repetition.

There is evidence in the literature that, if contextual information is very reliable, there will be little or no reliance on perceptual fluency (Jacoby \& Witherspoon, 1982; Johnston, Dark, \& Jacoby, 1985). On this view, to account for null findings of voice variation (see, e.g., Church \& Schacter, 1994) requires determining the variables that increased conceptually driven processing. Church and Schacter account for the null effects of voice variation in their experiments by stating that "subjects tend to rely on conceptually driven processes when engaging in explicit retrieval" (p. 532). The present results demonstrate that it is not just that recognition memory tests tend to be conceptually driven, but also that the distinctive stimulus materials selected by Church and Schacter fostered additional conceptual processing at encoding and retrieval. Note that this does not imply that voice information is poorly encoded, only that it is less likely to be retrieved in the service of recognition under these conditions.

As reviewed in the introduction, the amount of interitem organization evoked by the stimulus materials was cited as the most plausible source of the discrepant outcomes found across several recognition experiments. However, the experiments reported here and the experiments of Schacter and Church (1992) differed with respect to stimulus characteristics other than the degree to which the word list emphasized semantic relationships, thus admitting the possibility that other factors, such as word frequency (cf. Meehan \& Pilotti, 1996), word length, lexical density, or list length may be affecting the use of instance-specific perceptual information during recognition. Because the present experiments did not vary the nature of the stimulus materials within a single experiment, further research is needed to directly evaluate the hypothesis that sensitivity to voice information decreases as interitem elaboration increases.

To accommodate the fact that voice effects were found on an explicit memory task, the multiple memory system's account of the relation between voice and episodic information must be revised. As currently described (Church \& Schacter, 1994; Schacter \& Church, 1992), information about the spatiotemporal context of a word is retained in the episodic memory system, which functions in ways that are distinct from and incompatible with the functions of the PRS. Ostensibly, performance on implicit tasks is mediated by the PRS, which contains perceptual records of words that are devoid of meaning and context. By interpretation, without meaning or context, the output from the PRS cannot be experienced as an explicit memory per se but can only be experienced as a percept. In this way, the content of the PRS is well suited for facilitating the perceptual identification of words but is incompatible with the requirements of conscious recollection, which may be why the output from the PRS is assumed to be unavailable during episodic memory.

If this characterization of Schacter's PRS view is correct, the finding that study-to-test changes in voice affected explicit retrieval cannot be explained. Two modifications are needed to retain the PRS hypothesis and account for these effects. The first modification would be to allow interaction between the PRS and episodic memory. Recent studies by Schacter and his colleagues indicate that this theoretical move will probably be necessary to account for null voice-specificity effects among amnesics (Schacter, Church, \& Bolton, 1994) and elderly normals (Schacter, Church, \& Osowiecki, 1994). Specifically, Schacter, Church, and Osowiecki suggest that "voice-specific priming may require an interaction between the PRS and the episodic system" (p. 318) in order to bind word and speaker information. The idea is that, if the structures supporting episodic memory are impaired, as they are among amnesics and the elderly, voice information cannot be associated with word information, and voice variation cannot influence auditory word priming. So far, Schacter and his colleagues limit the description of the interaction between the episodic memory and PRS to one in which the former influences the latter and leave unspecified the degree (if any) to which the PRS can contribute to explicit retrieval. This latter interaction is what is needed to account for the voice-specificity effects in explicit memory. 
The second modification required by the systems view would be to specify how episodic memory can utilize the contribution from the PRS. In particular, if the perceptual output from the PRS cannot be intentionally brought into awareness and consciously used in the same manner as that in which episodes are, how can such information affect explicit memory? Process-oriented recognition memory frameworks (Jacoby, 1983; Mandler, 1980) currently provide a way in which unconscious perceptual information affects conscious recollection. Incorporating this or a similar perspective would allow the multiple memory systems view to explain format-specificity effects in recognition.

In conclusion, the fact that word recognition was affected by changes in voice is consistent with the idea that talker-specific perceptual information is represented in episodic memory, rather than in a memory system that is separate from episodic memory, and that voice information can affect performance of explicit memory.

\section{REFERENCES}

ANDERSON, J. R., \& BowER, G. H. (1973). Human associative memory. Washington, DC: Winston.

AtKinson, R. C., \& Juola, J. F. (1974). Search and decision processes in recognition memory. In D. H. Krantz, R. C. Atkinson, R. D. Luce, \& P. Suppes (Eds.), Contemporary developments in mathematical psychology: Vol. 1. Learning, memory and thinking (pp. 243-293). San Francisco: Freeman.

BLAXTON, T. A. (1989). Investigating dissociations among memory measures: Support for a transfer-appropriate processing framework. Journal of Experimental Psychology: Learning, Memory, \& Cognition, 15, 657-688.

Church, B., \& Schacter, D. (1994). Perceptual specificity of auditory priming: Implicit memory for voice, intonation and fundamental frequency. Journal of Experimental Psychology: Learning, Memory, \& Cognition, 20, 521-533.

Craik, F. I. M., \& Kirsner, K. (1974). The effects of speaker's voice on word recognition. Quarterly Journal of Experimental Psychology, 26, 274-284.

Craik, F. I. M., \& Lockhart, R. S. (1972). Levels of processing: A framework for memory research. Journal of Verbal Learning \& Verbal Behavior, 11, 671-684.

GARDINER, J. M. (1988). Functional aspects of recollective experience. Memory \& Cognition, 16, 309-313.

Gardiner, J. M., Gawlik, B., \& Richardson-Klavehn, A. (1994). Maintenance rehearsal affects knowing, not remembering; elaborative rehearsal affects remembering, not knowing. Psychonomic Bulletin \& Review, 1, 107-110.

Geiselman, R. E., \& Bellezza, F. S. (1977). Incidental retention of speaker's voice. Memory \& Cognition, 5, 658-665.

Geiselman, R. E., \& BJoRK, R. A. (1980). Primary versus secondary rehearsal in imagined voices: Differential effects on recognition. Cognitive Psychology, 12, 188-205.

GoldINGER, S. D. (1992). Words and voices: Implicit and explicit memory for spoken words (Tech. Rep. No. 7). Bloomington: Indiana University, Department of Psychology, Speech Research Laboratory.

GOLDINGER, S. D. (1996). Words and voices: Implicit and explicit memory for spoken words. Journal of Experimental Psychology: Learning, Memory, \& Cognition, 22, 1166-1183.

HintZMAN, D. L. (1986). "Schema abstraction" in a multiple-trace memory model. Psychological Review, 93, 411-428.

Hintzman, D. L., Block, R. A., \& Inskeep, N. R. (1972). Memory for the mode of input. Journal of Verbal Learning \& Verbal Behavior, 11 , $741-749$.

Hood, J. D., \& PoOLE, J. P. (1980). Influence of the speaker and other factors affecting speech intelligibility. Audiology, 19, 434-455.
House, A. S., Williams, C. E., Hecker, M. H. L., \& KRYter, K. D. (1965). Articulation-testing methods: Consonantal differentiation with a closedresponse set. Journal of the Acoustical Society of America, 37, 158-166.

JACKSON, A., \& MORTON, J. (1984). Facilitation of auditory word recognition. Memory \& Cognition, 12, 568-574.

JACOBY, L. (1983). Remembering the data: Analyzing interactive processes in reading. Journal of Verbal Learning \& Verbal Behavior, 22, 485-508.

JACOBY, L., \& DALLAS, M. (1981). On the relationship between autobiographical memory and perceptual learning. Journal of Experimental Psychology: General, 110, 306-340.

JACOBY, L., \& WIrHERSPOON, D. (1982). Remembering without awareness. Canadian Journal of Psychology, 36, 300-324.

Johnston, W. A., DARK, V. J., \& JACOBY, L. L. (1985). Perceptual fluency and recognition judgments. Journal of Experimental Psychology: Learning, Memory, \& Cognition, 11, 3-11.

Johnston, W. A., Hawley, K. J., \& Elliot, M. G. (1991). Contribution of perceptual fluency to recognition judgments. Journal of Experimental Psychology: Learning, Memory, \& Cognition, 17, $210-223$.

KIRSNER, K. (1973). An analysis of the visual component in recognition memory for verbal stimuli. Memory \& Cognition, 1, 449-453.

Kolers, P. A., \& Roediger, H. L., III (1984). Procedures of the mind. Journal of Verbal Learning \& Verbal Behavior, 23, 425-449.

KuČERA, F., \& FrANCIS, W. (1967). Computational analysis of presentday American English. Providence, RI: Brown University Press.

MandLer, G. (1980). Recognizing: The judgment of previous occurrence. Psychological Review, 87, 252-271.

Meehan, E. F., \& Pilotti, M. (1996). Auditory priming in an implicit memory task that emphasizes surface processing. Psychonomic Bulletin \& Review, 3, 495-498.

Miller, G. A., Heise, G. A., \& Lichten, W. (1951). The intelligibility of speech as a function of the context of the test materials. Journal of Experimental Psychology, 41, 329-335.

Miller, G. A., \& NiCEly, P. E. (1955). An analysis of perceptual confusions among some English consonants. Journal of the Acoustical Society of America, 43, $1165-1169$.

MorRIS, C. D., Bransford, J. P., \& Franks, J. J. (1977). Levels of processing versus transfer-appropriate processing. Journal of Verbal Learning \& Verbal Behavior, 16, 519-533.

Palmeri, T. J., Goldinger, S. D., \& Pisoni, D. B. (1993). Episodic encoding of voice attributes and recognition memory for spoken words. Journal of Experimental Psychology: Learning, Memory, \& Cognition, 19, 309-328.

PIsoni, D. B. (1993). Long-term memory in speech perception: Some new findings on talker variability, speaking rate and perceptual learning. Speech Communication, 13, 109-125.

Pisoni, D. B. (1996). Some thoughts on "normalization" in speech perception. In K. Johnson \& J. W. Mullennix (Eds.), Talker variability in speech processing (pp. 9-32). San Diego: Academic Press.

Remez, R. E., Fellowes, J. M., \& Rubin, P. E. (1997). Talker identification based on phonetic information. Journal of Experimental Psychology: Human Perception \& Performance, 23, 651-666.

RichARDSON-KLAVEHN, A., \& BJORK, R. A. (1988). Measures of memory. Annual Review of Psychology, 39, 475-543.

RoEDIGER, H. L., III (1990). Implicit memory: Retention without remembering. American Psychologist, 45, 1043-1056.

RoEdiger, H. L., III, \& MCDERMOTT, K. B. (1993). Implicit memory in normal human subjects. In H. Spinnler \& F. Boller (Eds.), Handbook of neuropsychology (Vol. 8, pp. 63-131). Amsterdam: Elsevier.

SCHACTER, D. L. (1987). Implicit memory: History and current status. Journal of Experimental Psychology: Learning, Memory, \& Cognition, $13,501-518$.

Schacter, D. L. (1992). Priming and multiple memory systems: Perceptual mechanisms of implicit memory. Journal of Cognitive Neuroscience, 4, 244-256.

SCHACTER, D. L., \& CHURCH, B. A. (1992). Auditory priming: Implicit and explicit memory for words and voices. Journal of Experimental Psychology: Learning, Memory, \& Cognition, 18, 915-930.

Schacter, D. L., Church, B. A., \& BolTon, E. (1994). Implicit memory in amnesic patients: Impairment of voice-specific priming. $P_{s y-}$ chological Science, 6, 20-25. 
Schacter, D. L., Church, B. A., \& Osowiecki, D. M. (1994). Auditory priming in elderly adults: Impairment of voice-specific implicit memory. Memory, 5, 295-323.

ShEFFERT, S. M. (1998). Voice-specificity effects on auditory word priming. Memory \& Cognition, 26, 591-598.

ShefFert, S. M., \& Fowler, C. A. (1995). The effects of voice and visible speaker change on memory for spoken words. Journal of Memory \& Language, 34, 665-685.

Sheffert, S. M., Fowler, C. A., Steinnagel, T., \& Behnken, K. (1995, April). Voice-specificity effects on spoken word recognition. Paper presented at the 1995 Eastern Psychological Association Annual Meeting, Boston.

SQuire, L. R. (1992). Memory and the hippocampus: A synthesis of findings with rats, monkeys, and humans. Psychological Review, 99, 195-231.

StudderT-Kennedy, M. (1974). The perception of speech. In T. A. Sebeok (Ed.), Current trends in linguistics (pp. 2349-2385). The Hague: Mouton.

Tulving, E. (1972). Episodic and semantic memory. In E. Tulving \& W. Donaldson (Eds.), Organization of memory (pp. 381-403). New York: Academic Press.

TUlving, E., \& SCHACTER, D. L. (1990). Priming and human memory systems. Science, 247, 301-306.

Van Lancker, D., Kreiman, J., \& Emmorey, K. (1985). Familiar voice recognition: Patterns and parameters: Part I. Recognition of backward voices. Journal of Phonetics, 13, 19-38.

VAN Lancker, D., Kreiman, J., \& WiCKens, T. (1985). Familiar voice recognition: Patterns and parameters: Part II. Recognition of ratealtered voices. Journal of Phonetics, 13, 39-52.

\section{NOTES}

1. The term voice refers to acoustic information other than information about the identity of a spoken word.

2 . The recognition test only presented items in the clear. Recognition in noise was not used, because it was deemed to be contaminated with implicit memory processes. In particular, because the task would rely heavily on perceptual identification, and perceptual identification of words in noise is sensitive to voice variation (see Sheffert, 1998), it would be impossible to know whether a voice effect on recognition memory performance was due to a physical match between study and test episodes or, instead, to retrieval from implicit memory. Consequently, results from recognition of words in noise would be impossible to interpret unambiguously.

3. When word recognition was not conditionalized on identification accuracy at study, the results were very similar. Overall, conditionalization increases the overall accuracy of word recognition, simply because the hardest-to-hear study items were eliminated from the test analysis. However, the pattern of voice effects (the difference between same- and different-voice recognition scores) is the same for the two analysis $(11.8 \%$ and $10.7 \%$ for clear study and $6.6 \%$ and $6.0 \%$ for noise study for the unconditionalized and conditionalized data, respectively).

4. I thank Douglas Hintzman for bringing this problem to my attention.

\begin{tabular}{|c|c|c|c|c|c|}
\hline & & $\begin{array}{r}\mathbf{A P} \\
\text { Stimul }\end{array}$ & $\begin{array}{l}\text { JDIX } \\
\text { Iateri? }\end{array}$ & & \\
\hline lace & yawn & beam & men & boil & buff \\
\hline rose & dud & bed & shook & seed & cold \\
\hline neat & song & ink & tin & fit & pad \\
\hline coil & bad & race & rock & dark & bale \\
\hline quiz & curb & dip & fold & tone & joke \\
\hline knob & fig & case & wig & rig & mass \\
\hline jazz & kit & cuff & pay & ape & heave \\
\hline wit & heat & ray & duck & surf & map \\
\hline tame & pup & hot & just & gin & fame \\
\hline zip & dug & back & save & chalk & lake \\
\hline shine & heap & path & cane & lit & sit \\
\hline $\operatorname{dim}$ & page & lay & rent & cake & screen \\
\hline tick & door & $a x$ & cop & cub & pane \\
\hline posh & feel & pace & bog & teach & shop \\
\hline hang & test & pun & tack & $\operatorname{limb}$ & cape \\
\hline top & big & salt & sung & reel & hill \\
\hline meat & sang & pill & dust & gear & late \\
\hline king & heel & pan & mash & cave & health \\
\hline pack & west & fall & mat & lot & goat \\
\hline vest & sent & hear & same & look & bust \\
\hline teal & led & peace & pat & jaw & raw \\
\hline young & soil & must & tap & cup & will \\
\hline kid & mop & dent & way & bent & rust \\
\hline rang & hip & seek & sane & knot & tot \\
\hline ridge & bang & dig & pale & park & paw \\
\hline moss & peal & mark & sun & lark & eel \\
\hline worm & kick & bat & folk & beach & fang \\
\hline sake & suds & fib & pin & book & phone \\
\hline quake & best & seen & cook & say & game \\
\hline peak & wed & pig & rip & feat & sold \\
\hline vote & hop & hold & gig & pair & seep \\
\hline kale & gold & tale & sing & may & shoe \\
\hline fetch & took & booth & bit & bean & kill \\
\hline nest & bill & fed & oil & team & peach \\
\hline pick & plug & told & chief & cut & fox \\
\hline puff & tease & shed & void & gang & \\
\hline beat & ice & pave & rake & sick & \\
\hline done & teak & bun & bug & lane & \\
\hline group & bus & pen & safe & some & \\
\hline thaw & hook & pop & heal & tent & \\
\hline vogue & sale & hark & saw & pace & \\
\hline
\end{tabular}

(Manuscript received March 21, 1997 ; revision accepted for publication August 30, 1997.) 